Supporting Information for:

\title{
Molecular-Level Photo-Orientation Insights into Macroscopic Photo-Induced Motion in Azobenzene-Containing Polymer Complexes
}

Mahnaz Kamaliardakani, ${ }^{1}$ Jaana Vapaavuori, ${ }^{1, \dagger}$ Xiaoxiao Wang, ${ }^{1}$ Ribal Georges Sabat, ${ }^{2}$ C. Geraldine Bazuin, ${ }^{*}, 1$ Christian Pellerin ${ }^{*}, 1$

${ }^{1}$ Département de chimie, Université de Montréal, C.P. 6128, succursale Centre-Ville, Montréal, QC, Canada H3C 3J7

${ }^{2}$ Department of Physics and Space Science, Royal Military College of Canada, Kingston, ON, Canada K7K 7B4

† Current address: Department of Chemistry and Materials Science, School of Chemical Engineering, Aalto University, Kemistintie 1, 02150 Espoo, Finland

Emails of corresponding authors: geraldine.bazuin@umontreal.ca; c.pellerin@umontreal.ca 


\section{Section A. ${ }^{1} \mathrm{H}$ NMR Analysis}

For H-bonded complexes, the 1:1 azoOH:VP molar ratio can be confirmed using the integrated intensities of either signal e, h or signal g, $\mathrm{f}(\mathrm{azoOH})$ and either signal c or signal b (P4VP). Figure S1a for azoOH/ $\mathrm{P}_{480}$ shows that the H-bonded complexation is essentially equimolar. Signal d, which is ascribed to the proton of the $\mathrm{OH}$ group of the azo, is found at 10.0 ppm but cannot be considered as a sign of H-bonding in the complexes since its chemical shift is the same in the spectrum of pure azoOH (not shown) due to hydrogen bonding with the solvent. In fact, the narrow azoOH peaks compared to those of P4VP indicate that complexation is not maintained in solution due to competition for H-bonding with the solvent molecules. Nevertheless, the combined NMR and IR results (section B) validate the equimolar composition and high degree of complexation in the H-bonded complexes.

The essentially complete quaternization of $\mathrm{P}_{\mathrm{DP}}(\mathrm{P} 4 \mathrm{VP})$ to $\mathrm{qP}_{\mathrm{DP}}(\mathrm{P} 4 \mathrm{VPMe})$ is verified by ${ }^{1} \mathrm{H}$ NMR in Figure S1b for DP 480, where the ratio of signal d to signal c is very close to 1.5 and the non-quaternized pyridine signals at 6.59 and 8.26 ppm are absent. Figure S1c for DP 480 validates the equimolar ratio in the i-bonded azoSO $3 / \mathrm{qP}_{\mathrm{DP}}$ complexes by comparison of the integrated intensities of the $\mathrm{azoSO}_{3}$ peaks (signals e or i) to the $\mathrm{qP}$ DP peaks (signals c or $\mathrm{d}$ ). ${ }^{1-2}$ The broad shape of all $\mathrm{azoSO}_{3}$ peaks in the spectrum of the i-bonded complex, compared with the narrow peaks for pure $\mathrm{azoSO}_{3}$ (Figure S1d) in DMSO, indicates a decreased mobility of azoSO $\mathrm{S}_{3}$ when i-bonded to P4VPMe. 

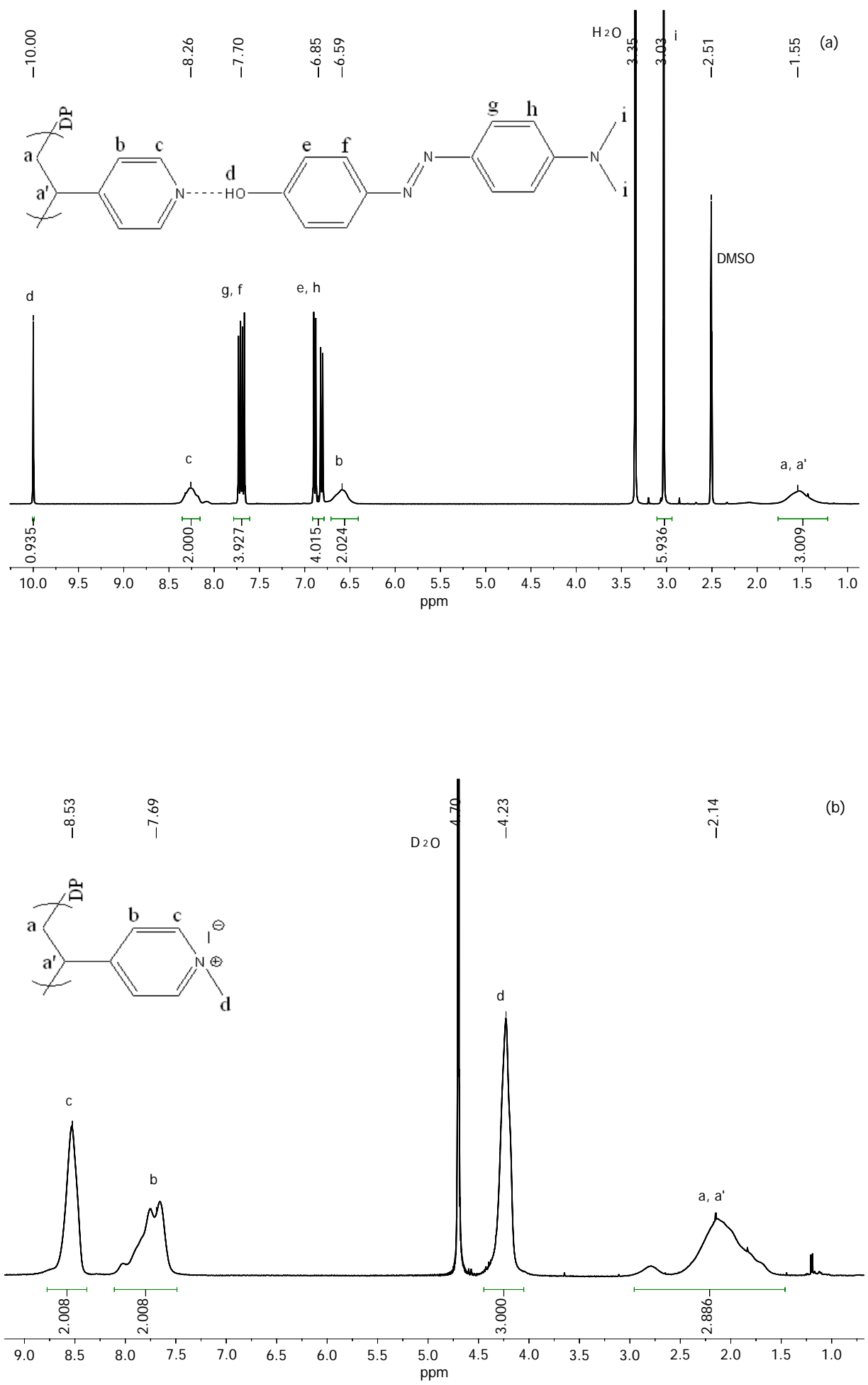

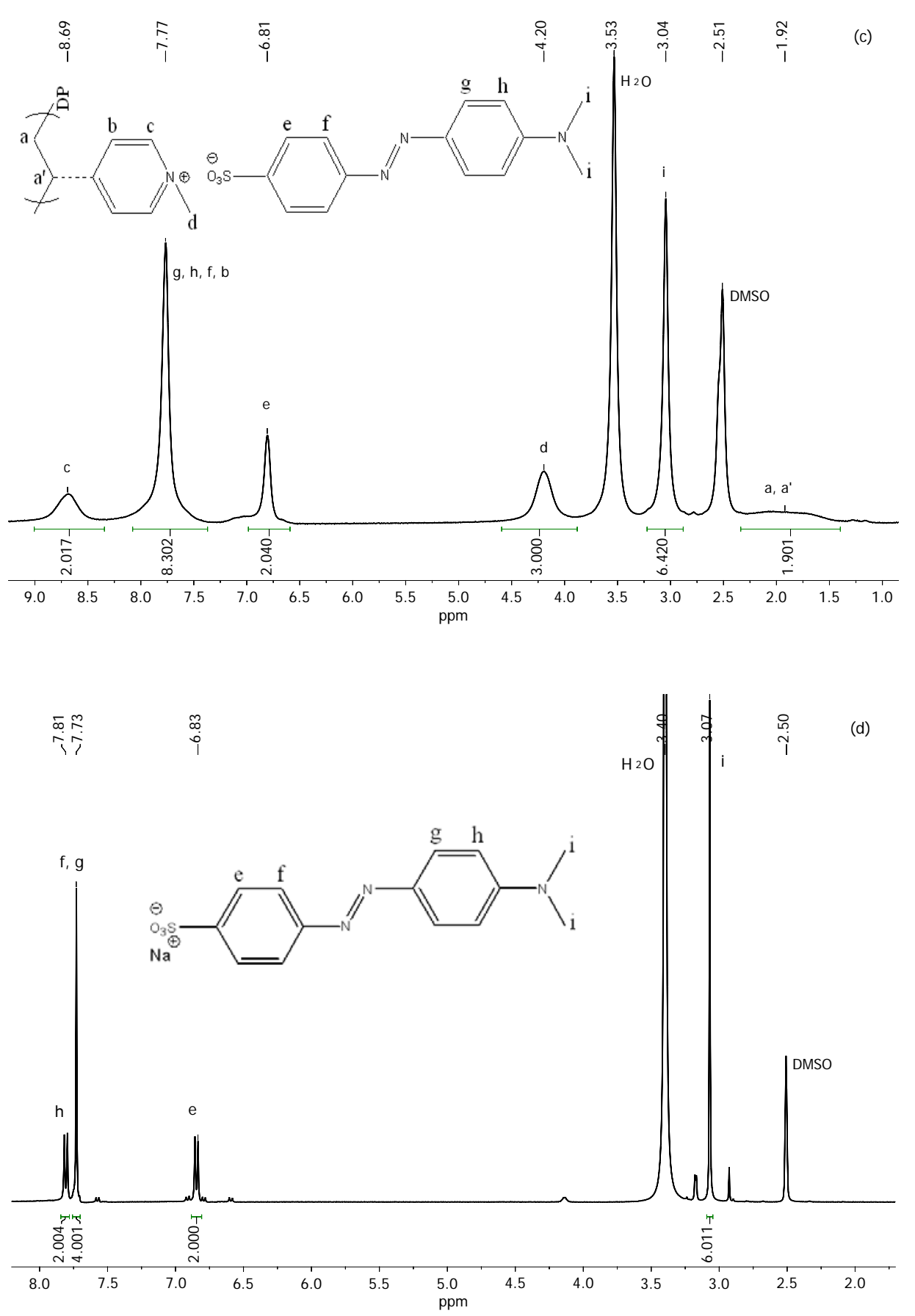

Figure S1. ${ }^{1} \mathrm{H}$ NMR spectra of (a) the azoOH/P 480 complex in DMSO-d 6 , (b) $\mathrm{qP}_{480}$ in $\mathrm{D}_{2} \mathrm{O}$, (c) the $\operatorname{azoSO}_{3} / \mathrm{qP}_{480}$ complex in DMSO- $\mathrm{d}_{6}$, and (d) pure $\mathrm{azoSO}_{3}$ in DMSO- $\mathrm{d}_{6}$. The numbers associated with the signals indicate the integration values. The spectra were normalized based on signals c, d, d, and e for panels (a), (b), (c), and (d), respectively. 


\section{Section B. Additional Infrared Spectroscopy Results}

The IR spectra in Figure S2 validate the essentially complete quaternization of $\mathrm{PDP}_{\mathrm{DP}}$ to qPDP.

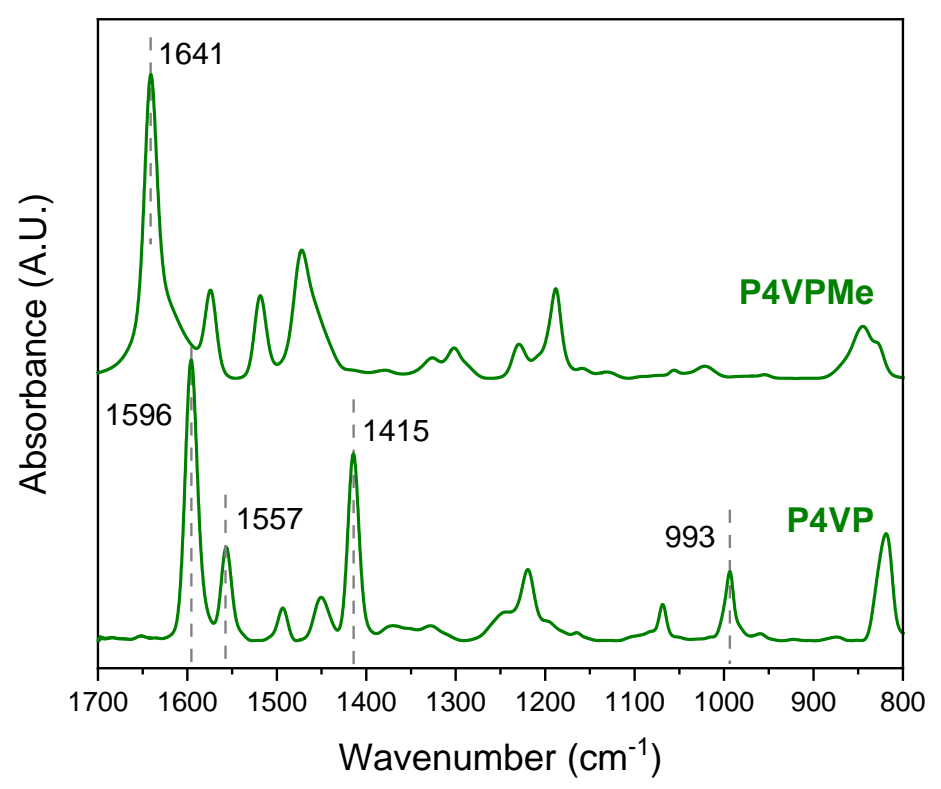

Figure S2. Infrared spectra of pure $\mathrm{P}_{\mathrm{DP}}(\mathrm{P} 4 \mathrm{VP})$ and pure quaternized qPDP (P4VPMe) of DP 480, showing the essentially complete disappearance of the pyridine bands at 1596, 1557, 1415 and 993 $\mathrm{cm}^{-1}$ and the appearance of the pyridinium band at $1641 \mathrm{~cm}^{-1}$ in the qPDP spectrum

The H-bond complexation between azoOH and P4VP in the solid state can be confirmed by IR spectroscopy. Figure S3 compares the second derivative of the transmission IR spectrum of a spin-coated film of the azoOH/ $/ 480$ complex with the second derivatives of the ATR-IR spectra of the pure components. The $993 \mathrm{~cm}^{-1}$ band in the spectrum of pure $\mathrm{P}_{480}$, which is due to a stretching mode of the free pyridine ring, shifts to $1008 \mathrm{~cm}^{-1}$ in the spectrum of the azoOH/P 480 complex. This band shift confirms the formation of a hydrogen bond between the pyridine ring and the hydroxyl group of azoOH, although a small residual band at $993 \mathrm{~cm}^{-1}$ (which is also partially overlapped with an azoOH band at around $996 \mathrm{~cm}^{-1}$ ) indicates that complexation is not altogether complete. The amplitude of the shift is consistent with previous observations for P4VP complexes with various hydroxyl-terminated small molecules and indicates a hydrogen bonding interaction of moderate strength..$^{3-5}$ 


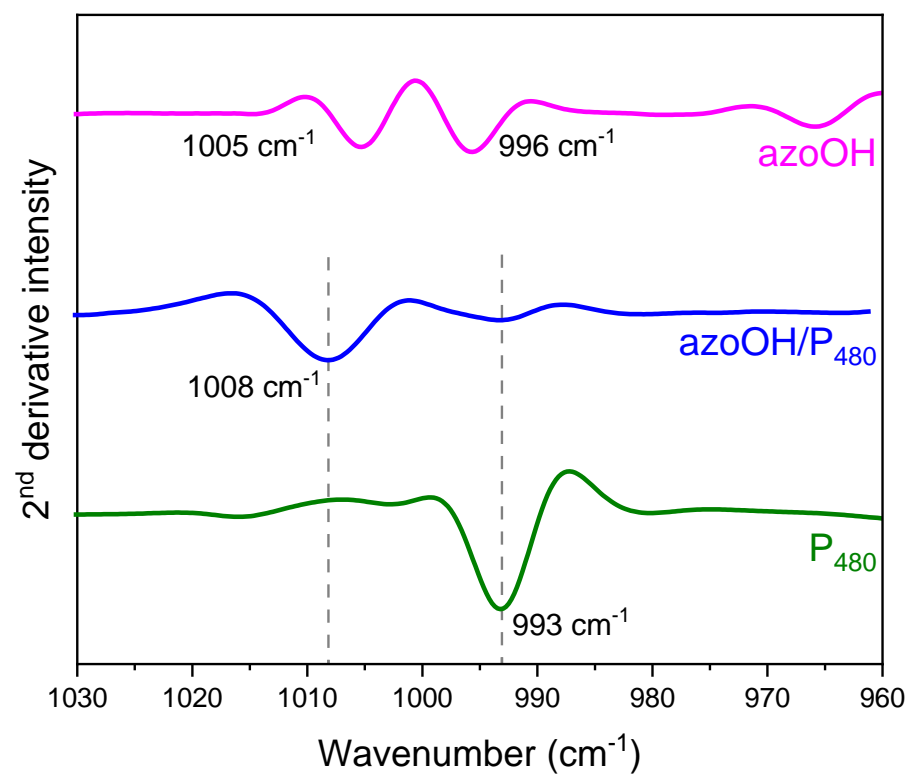

Figure S3. Second derivative IR spectra of pure $\mathrm{P}_{480}$, pure azoOH, and the azoOH/ $\mathrm{P}_{480}$ complex. All bands appear as negative peaks in second derivative spectra. 


\section{Section C. Additional SRG Inscription Results}

A)

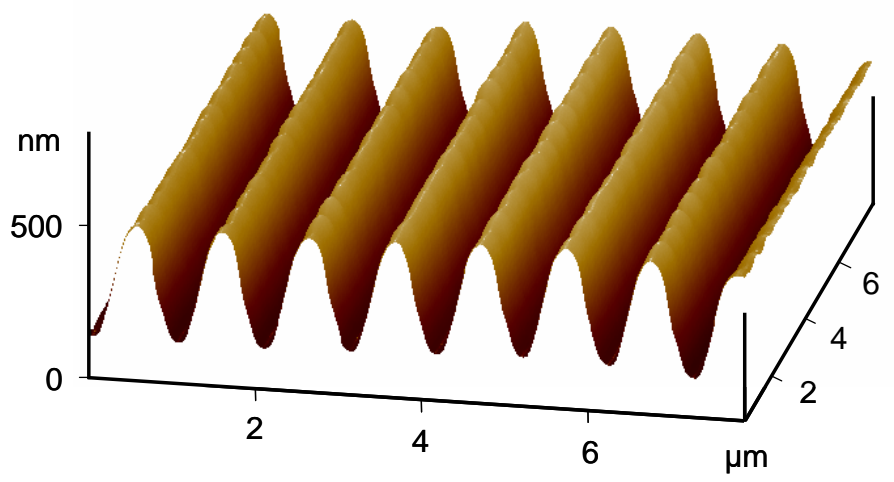

B)

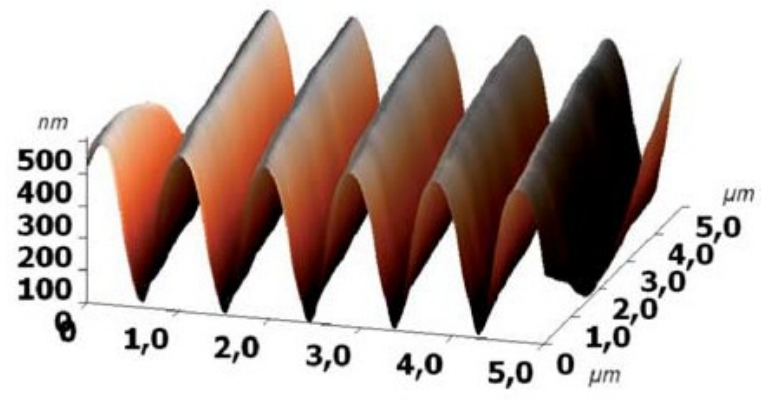

Figure S4. Examples of previously published atomic force microscopy (AFM) surface profiles of optically inscribed SRGs in spin-coated complex films: A) an equimolar azoSO $3 / \mathrm{qP}_{1900}$ complex and B) a 0.33 molar azoOH/qP10 (ref 6 shows an AFM image for this sample only as it presented the highest SRG formation efficiency and quality). In both cases, the SRG inscription conditions (laser wavelength and irradiance range, LCP-RCP irradiation configuration) were similar to those used in this manuscript. The amplitudes of the two SRG's are similar, consistent with the DE's in Figure 2 in the main text, considering that the DE increases with decrease in DP in the oligomeric range and therefore the $\mathrm{DE}$ for azoOH/ $\mathrm{P}_{10}$ should be significantly higher than that for $\mathrm{azoOH} / \mathrm{P}_{41}$. Panel A is reproduced from ref 2 (Figure 10); Panel B is reproduced from ref 6 (Figure 4a) with permission the Royal Society of Chemistry. 

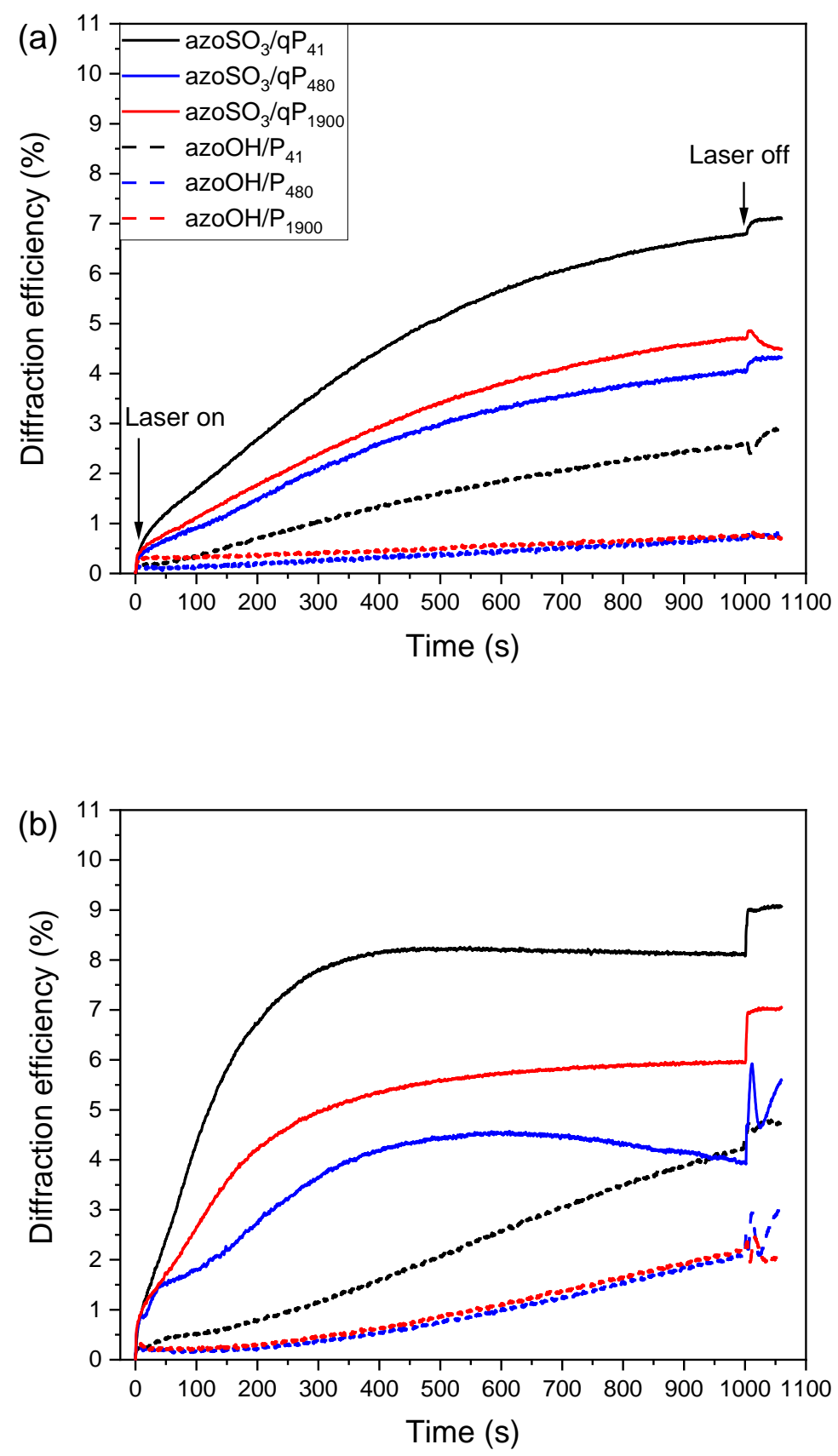

Figure S5. Diffraction efficiency of surface relief grating formation as a function of irradiation time for the H-bonded azoOH/PDP and i-bonded azoSO3/qPDP complexes indicated at irradiances of (a) 100 and (b) $400 \mathrm{~mW} / \mathrm{cm}^{2}$. 
Table S1. Maximum diffraction efficiency (\%) of the azocomplexes as a function of laser irradiance and degree of polymerization. Uncertainties are based on measurements on 2-4 samples. Values are rounded to one significant figure when a single measurement is available.

\begin{tabular}{lcccc}
\hline & DP & \multicolumn{3}{c}{ Irradiance $\left(\mathbf{m W ~ \mathbf { ~ m } ^ { - 2 } )}\right.$} \\
& 41 & $2.6 \pm 0.3$ & $3.4 \pm 0.2$ & $4.5 \pm 0.8$ \\
\hline $\mathbf{a z o O H} / \mathbf{P}_{\mathbf{D P}}$ & 480 & 0.7 & $1.5 \pm 0.2$ & $2.1 \pm 0.5$ \\
& 1900 & $0.7 \pm 0.1$ & $1.1 \pm 0.3$ & $2.1 \pm 0.2$ \\
\hline & 41 & $7 \pm 1$ & $8.6 \pm 0.3$ & $8.1 \pm 0.3$ \\
$\mathbf{a z o S O}_{3} / \mathbf{q P}_{\mathbf{D P}}$ & 480 & 4 & $4.9 \pm 0.2$ & 5 \\
& 1900 & $4.7 \pm 0.2$ & $5.4 \pm 0.1$ & $5.9 \pm 0.1$ \\
\hline
\end{tabular}




\section{Section D. Additional PM-IRSAS Results}
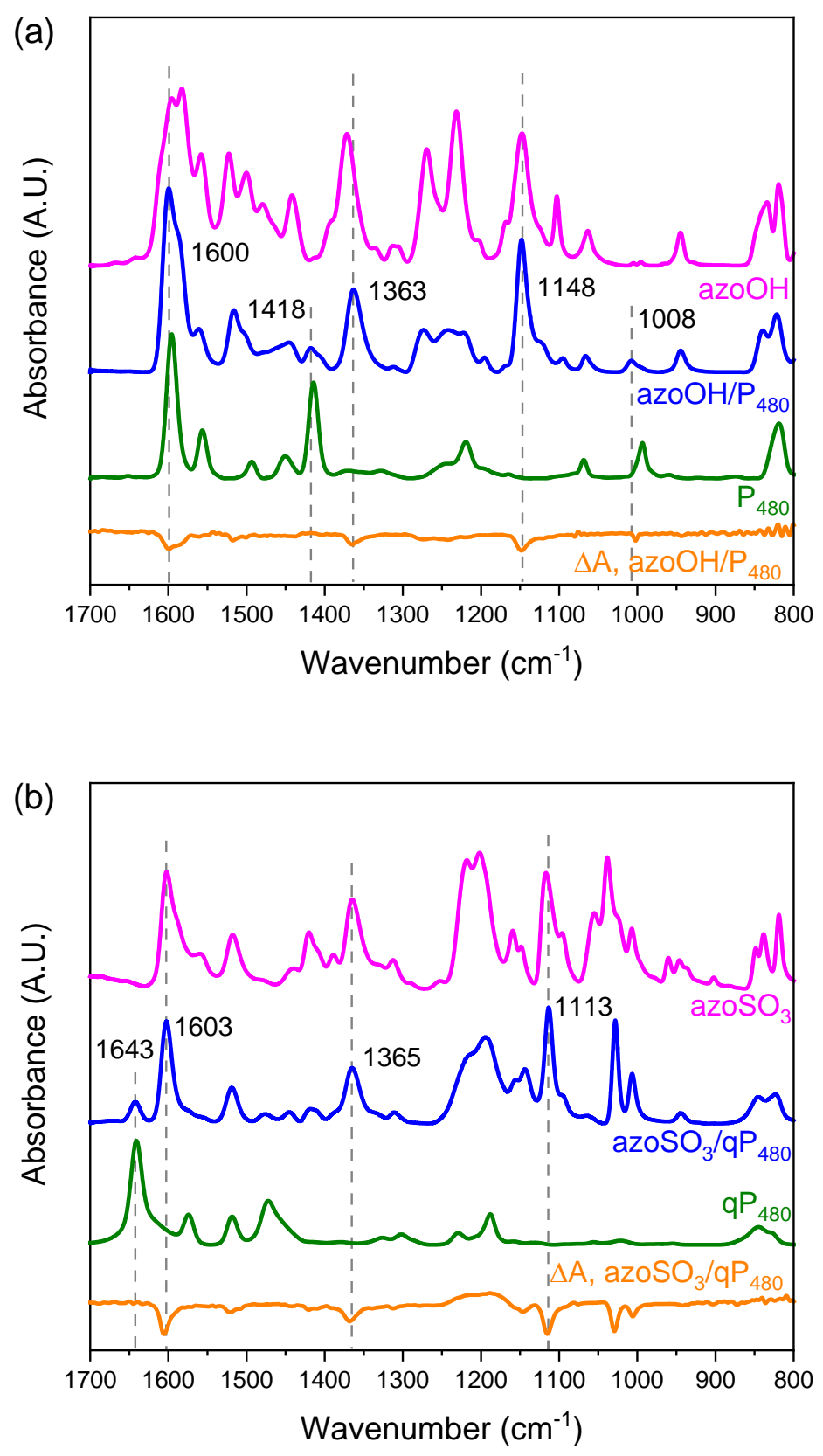

Figure S6. Infrared structural absorbance spectra ( $A_{0}$, blue) and dichroic difference spectra $(\triangle A$, orange) of irradiated spin-coated films of (a) $\mathrm{H}$-bonded $\mathrm{azoOH} / \mathrm{P}_{480}$ and (b) i-bonded $\mathrm{azoSO}_{3} / \mathrm{qP}_{480}$ complexes compared to the ATR-IR spectra of the pure compounds (azo in magenta, polymer in green). The azo-containing spectra are normalized with respect to the $1148 \mathrm{~cm}^{-1} \mathrm{azoOH}$ and the $1113 \mathrm{~cm}^{-1} \mathrm{azoSO}_{3}$ bands in (a) and (b), respectively. The dichroic difference spectrum in panel (a) is multiplied by 3 for clarity. 

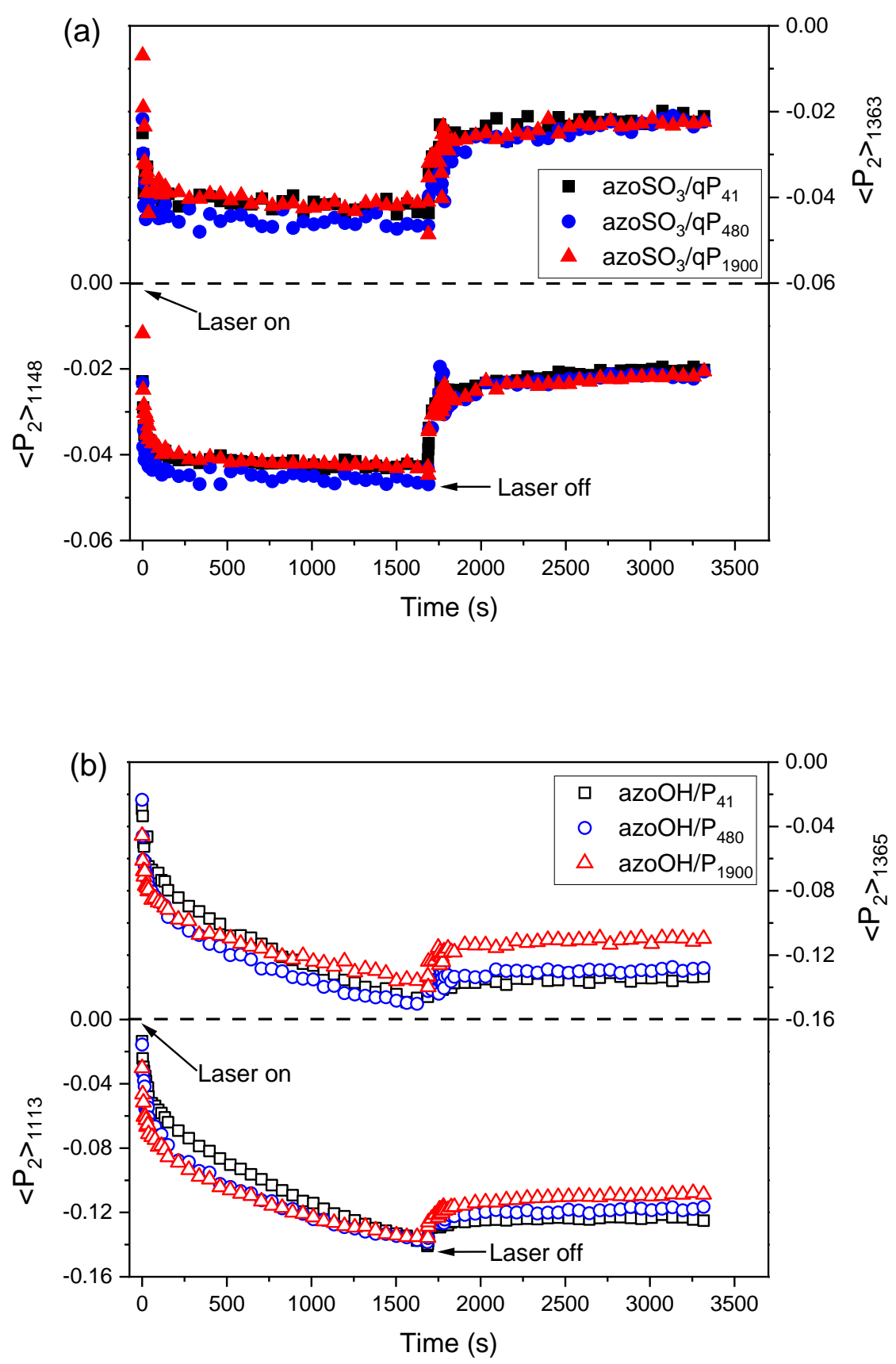

Figure S7. Photoinduced orientation $\left(<P_{2}>\right)$ as a function of time during orientation (laser on) and thermal relaxation (laser off) for (a) 1148 and $1363 \mathrm{~cm}^{-1} \mathrm{azoOH}$ bands of the azoOH/PDP complexes and (b) 1113 and $1365 \mathrm{~cm}^{-1}$ azoSO$_{3}$ bands of the azoSO $3 / \mathrm{qP}_{\mathrm{DP}}$ complexes. 

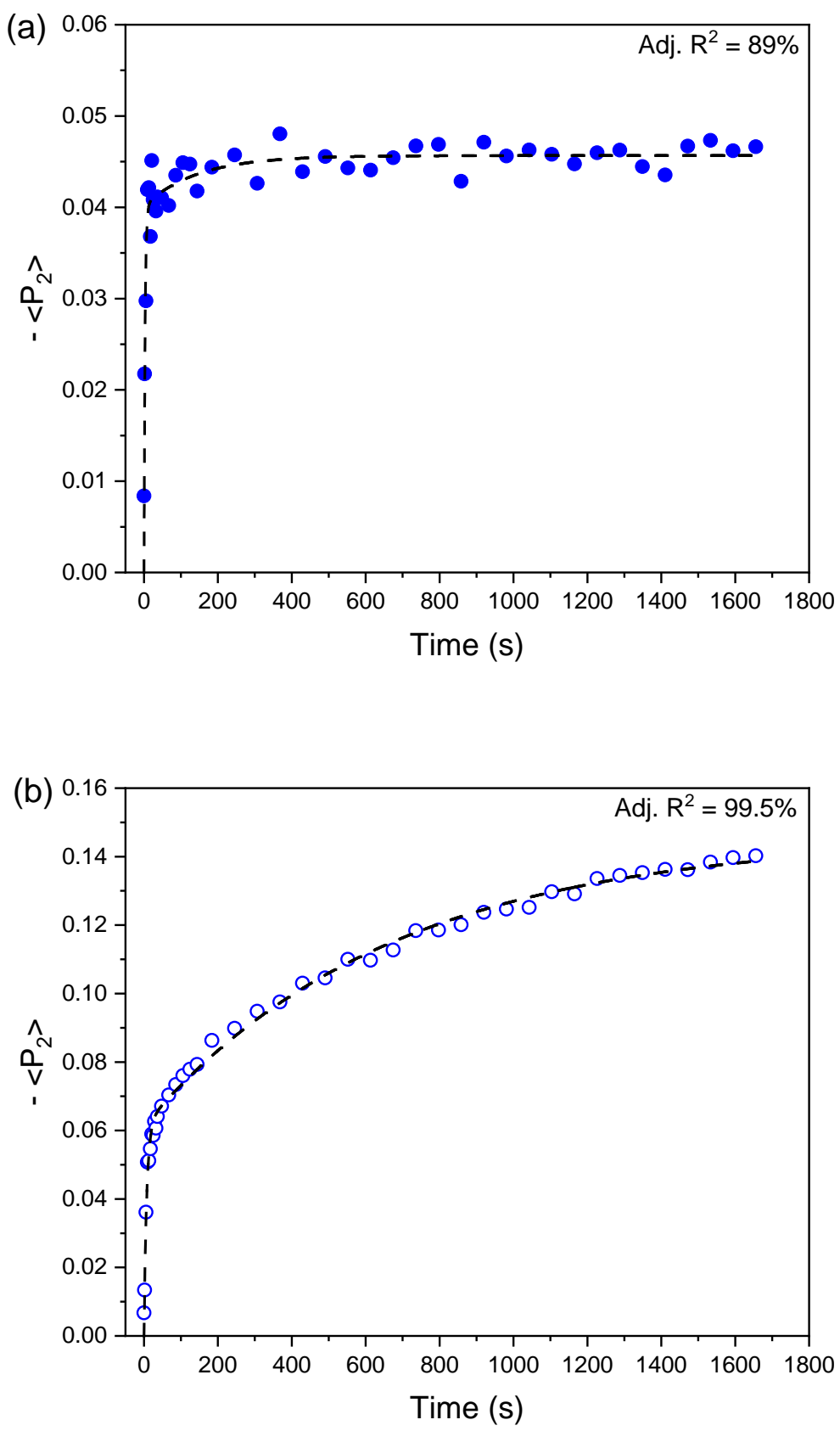

Figure S8. Representative curve fits of the photoorientation tracked by (a) the $1363 \mathrm{~cm}^{-1} \mathrm{azoOH}$ band of the azoOH/ $/ 480$ complex and (b) the $1365 \mathrm{~cm}^{-1} \mathrm{azoSO}_{3}$ band of the $\mathrm{azoSO}_{3} / \mathrm{qP}_{480}$. Dashed lines are fits using the biexponential function, Equation 3 . The $<P_{2}>$ values were multiplied by -1 . 

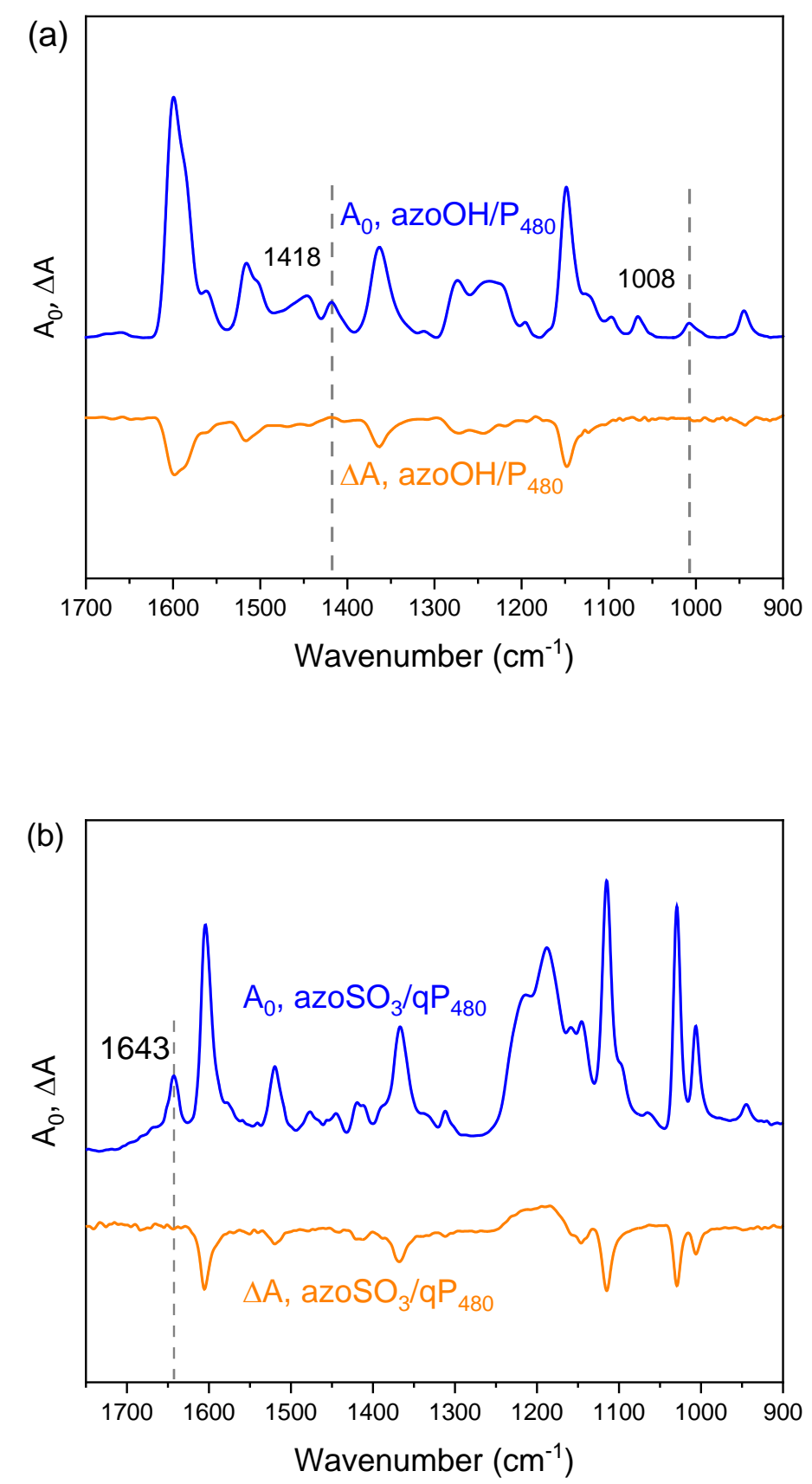

Figure S9. Infrared structural absorbance spectra $\left(A_{0}\right)$ and dichroic difference spectra $(\triangle A)$ measured in situ after 1000-s irradiation of (a) the $\mathrm{azoOH} / \mathrm{P}_{480}$ complex and (b) the $\mathrm{azoSO}_{3} / \mathrm{qP}_{480}$ complex. The dichroic difference spectrum in panel (a) is multiplied by 2 for clarity. 


\section{References}

1. Zhang, Q.; Bazuin, C. G.; Barrett, C. J., Simple Spacer-Free Dye-Polyelectrolyte Ionic Complex: Side-Chain Liquid Crystal Order with High and Stable Photoinduced Birefringence. Chem. Mater. 2008, 20, 29-31, DOI: 10.1021/cm702525y.

2. Zhang, Q.; Wang, X.; Barrett, C. J.; Bazuin, C. G., Spacer-Free Ionic Dye-Polyelectrolyte Complexes: Influence of Molecular Structure on Liquid Crystal Order and Photoinduced Motion. Chem. Mater. 2009, 21, 3216-3227, DOI: 10.1021/cm900810r.

3. Roland, S.; Gaspard, D.; Prud'homme, R. E.; Bazuin, C. G., Morphology Evolution in Slowly Dip-Coated Supramolecular PS-b-P4VP Thin Films. Macromolecules 2012, 45, 5463-5476, DOI: $10.1021 / \mathrm{ma3007398.}$.

4. Roland, S.; Pellerin, C.; Bazuin, C. G.; Prud'homme, R. E., Evolution of Small Molecule Content and Morphology with Dip-Coating Rate in Supramolecular PS-P4VP Thin Films. Macromolecules 2012, 45, 7964-7972, DOI: 10.1021/ma301383v.

5. Wang, X.; Bazuin, C. G.; Pellerin, C., Quantitative Analysis of Hydrogen Bonding in Electrospun Fibers of Poly(4-vinyl pyridine)/(4,4'-Biphenol) Complexes by ATR using Liquid Blends as Models. Vib. Spectrosc. 2014, 71, 18-23, DOI: 10.1016/j.vibspec.2013.12.011.

6. Vapaavuori, J.; Valtavirta, V.; Alasaarela, T.; Mamiya, J.-I.; Priimagi, A.; Shishido, A.; Kaivola, M., Efficient Surface Structuring and Photoalignment of Supramolecular PolymerAzobenzene Complexes through Rational Chromophore Design. J. Mater. Chem. 2011, 21, 15437-15441, DOI: 10.1039/c1jm12642c. 